\title{
FLT3 Inhibitor SKI-G-801
}

National Cancer Institute

\section{Source}

National Cancer Institute. FLT3 Inhibitor SKI-G-801. NCI Thesaurus. Code C155773.

An orally bioavailable inhibitor of both wild type and mutant forms of FMS-like tyrosine kinase 3 (FLT3; CD135; ST K1; FLK2), with potential antineoplastic activity. Upon administration, FLT 3 inhibitor SKI-G-801 binds to and inhibits the activity of FLT3, including FLT3-ITD (internal tandem duplications), FLT3-D835Y as well as other mutants. This inhibits uncontrolled FLT3 signaling and results in the inhibition of proliferation in tumor cells overexpressing FLT3. FLT3, a class III receptor tyrosine kinase (RTK), is overexpressed or mutated in most B lineage neoplasms and in acute myeloid leukemias, and plays a key role in tumor cell proliferation. In addition, SKI-G-801 also inhibits, to a lesser degree, the receptor tyrosine kinases AXL (UFO), Mer, Ret, vascular endothelial growth factor receptor 1 (VEGFR1), Fms, fibroblast growth factor receptors (FGFR) 1 and 3, and the serine/threonine kinases Aurora B and C. 